\title{
PENERAPAN LOGIKA FUZZY UNTUK MENENTUKAN KONDISI MESIN PADA MOTOR TRANSMISI MANUAL (STUDI KASUS HONDA CS-1)
}

\author{
Eric Teguh Ariyanto \\ Fakultas Sains dan Matematika, Departemen Ilmu Komputer / Informatika \\ Universitas Diponegoro \\ Email: eric.ariyanto555@gmail.com \\ Sutikno \\ Fakultas Sains dan Matematika, Departemen Ilmu Komputer / Informatika \\ Universitas Diponegoro \\ Email: tik@undip.ac.id
}

\begin{abstract}
ABSTRAK
Honda CS-1 merupakan salah satu jenis sepeda motor dengan transmisi manual dengan spesifikasi mesin SOHC (Single Overhead Camshaft). Untuk melakukan perawatan mesin tersebut dibutuhkan pengetahuan yang cukup. Beberapa mekanik memiliki tingkat pengetahuan yang berbeda sehingga dimungkinkan terdapat kesalahan dalam melakukan perawatan mesin.Untuk menghindari kesalahan tersebut, maka perlu dirancang sebuah aplikasi untuk membantu mekanik melakukan analisa kondisi mesin tersebut, sehingga mekanik dapat menganalisa letak kerusakan mesin dan memberikan saran penanganan yang tepat.Metode yang digunakan adalah metode mamdani. Dari hasil pengujian aplikasi ini didapatkan bahwa error rate untuk menentukan kondisi kerusakan mesin adalah $10 \%$. Hal ini berarti bahwa aplikasi sudah dapat diterapkan untuk membantu mekanik untuk menentukan kondisi kerusakan mesin motor Honda CS-1.
\end{abstract}

Kata kunci: logika fuzzy, mamdani, honda CS-1.

\begin{abstract}
Honda CS-1 is one type of motorcycle with a manual transmission with the engine specifications SOHC (Single Over head Camshaft). It takes considerable knowledge to be able to perform maintenance of the engine. Some mechanics have different levels of knowledge so it is possible there are errors in the machine maintenance. For that we need an application designed to help mechanics to analyze the condition of the engine, so it can analyze the mechani cal layout engine damage and give appropriate treatment.The method used is mamdani method. From the results of application testing it was found that the error rate to analyze condition of the damaged engine is $10 \%$. This means that the application can be applied to help mechanic to analyze level of the damaged engine.
\end{abstract}

Keywords: fuzzy logic, mamdani, honda CS-1.

\section{PENDAHULUAN}

Logika fuzzy merupakan salah satu bagian dari kecerdasan buatan.Logika fuzzy digunakan untuk memecahkan ketidakpastian penyebab dari suatu masalah. Dengan logika fuzzy dapat diketahui penyebab dari suatu masalah tersebut, sehingga dapat diambil suatu kesimpulan yang pasti. Logika fuzzy banyak digunakan karena diantaranya memiliki toleransi terhadap data-data yang tidak tepat/pasti [1]. Penggunaan dari metode ini diantaranya di gunakan pada pengendalian dan sistem pendukung keputusan. Penerapan logika fuzzy pada sistem pendukung keputusan diantaranya yaitu untuk diagnosis demam tifoid, manajemen krisis, penjadwalan irigasi, diagnosis penyakit asma, pengobatan penyakit rematik, dan pemilihan makanan ternak [2][3][4][5][6][7][8].

Dalam kehidupan sehari-hari, sering ditemukan masalah ketidakpastian, salah satunya adalah dalam perawatan mesin sepeda motor transmisi manual terutama untuk sepeda motor dengan spesifikasi mesin tinggi. Salah satu jenis motor dengan spesifikasi tinggi yaitu Honda CS-1 dengan mesin SOHC (Single Overhead Camshaft) 125CC. Jenis motor tersebut membuat mekanik perlu memiliki pengalaman dan pengetahuan yang cukup untuk melakukan analisa kondisi mesin sehingga dapat dilakukan tindakan perawatan yang tepat guna dan tepat sasaran. Namun, fakta yang ditemukan di lapangan masih terdapat perbedaan analisa kondisi mesin dari beberapa mekanik baru yang belum memeiliki pengalaman dan 
pengetahuan yang cukup sehingga menimbulkan perbedaan dan ketidakpastian tindakan perawatan (fuzziness).

Berdasarkan hal di atas, pada artikel ini mencoba menerapkan logika fuzzy untuk menentukan kondisi mesin pada motor transmisi manual studi kasus Honda CS-1 yang di implementasikan dalam aplikasi, guna memberikan pandangan analisa yang sama kepada mekanik baru dengan menggunakan basis pengetahuan dari mekanik yang telah memiliki pengetahuan dan pengalaman yang cukup.

\section{METODELOGI PENELITIAN} gambar 1.

Metodelogi penelitian yang di gunakan dalam penelitian ini meliputi langkah-langkah seperti pada

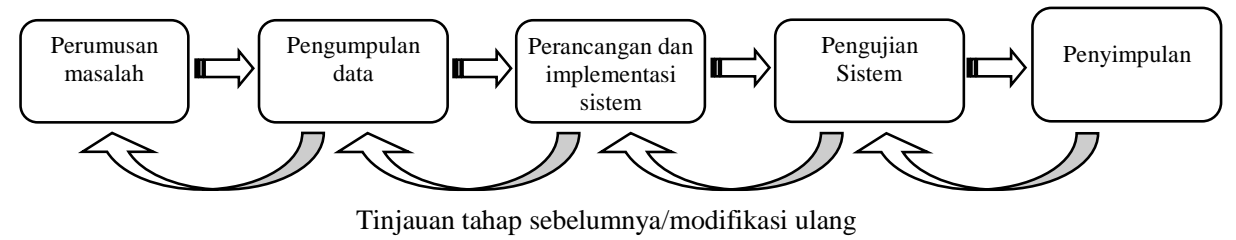

\section{Gambar 1. Metode Yang Digunakan Pada Penelitian}

Penjelasan dari masing-masing proses yaitu sebagai berikut:

a. Merumuskan permasalahan

Mengidentifikasi faktor apa saja yang terkait dengan bahan objek penelitian dalam bentuk pertanyaan.

b. Pengumpulan data

Mengumpulkan keterangan-keterangan dan informasi baik secara teori maupun fakta di lapangan.

c. Perancangan dan implementasi sistem

Mengidentifikasi kebutuhan dan spesifikasi sistem serta melakukan rancangan desain sistem kemudian mengimplementasikan hasil peracangan sistem dalam bentuk program yaitu dengan menggunakan bahasa pemrograman Microsoft Visual Studio 2012, DBMS MySQL versi 5.0.45.

d. Pengujian sistem

Melakukan pembandingan hasil pengolahan data secara manual dengan hasil data pengujian sistem yang dibangun, sehingga diketahui tingkat akurasi sistem. Untuk mengetahui tingkat error hasil pengujian di gunakan APER (Apparent Error Rate) [9].

e. Penarikan Kesimpulan

Menarik suatu kesimpulan yang didasarkan dari hasil pengolahan data dan pengujian sistem.

\section{HASIL PENELITIAN DAN PEMBAHASAN}

\subsection{Alur Sistem}

Alur sistem menjelaskan urutan proses sistem dari mulai input sampai ouput hasil. Alur sistem dapat dilihat pada gambar 2 .

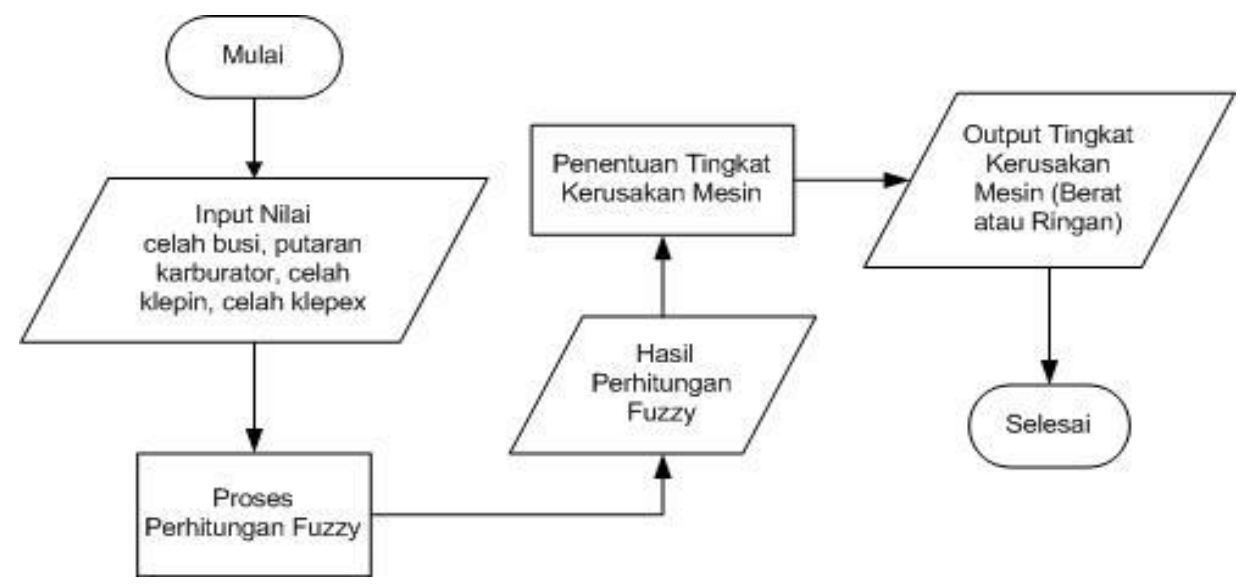

Gambar 2. Alur Sistem 
Penjelasan gambar 2 :

a. Input nilai kondisi tiap-tiap variabel (celah busi, putaran karburator, celah klep in, dan celah klep ex) sesuai dengan kondisi yang ditemukan di lapangan

b. Sistem melakukan perhitungan terhadap nilai input menggunakan fuzzy metode mamdani.

c. Nilai hasil proses hasil perhitungan fuzzy didapat.

d. Menggunakan nilai hasil proses perhitungan untuk menentukan tingkat kerusakan mesin. Penentuan tingkat kerusakan mesin didapatkan dari hasil uji perhitungan dan diskusi dengan narasumber.

e. Output berupa tingkat kerusakan mesin yaitu tingkat kerusakan mesin berat atau tingkat kerusakan mesin ringan.

\subsection{Pembentukan Himpunan Fuzzy}

Fuzzifikasi merupakan proses mengubah bilangan crips (tegas) menjadi bilangan fuzzy. Pemilihan variabel-variabel dan semesta pembicaraan yang digunakan dalam sistem iniberdasarkan dari studi pustaka dan diskusi dengan narasumber Bapak Sarifudin, beliau merupakan mekanik senior di dealer service motor Honda di Slawi. Variabel-variabel yang digunakan yaitu :

a. Celah Busi

Himpunan fuzzy untuk variabel celah busi dapat dilihat pada gambar 3.

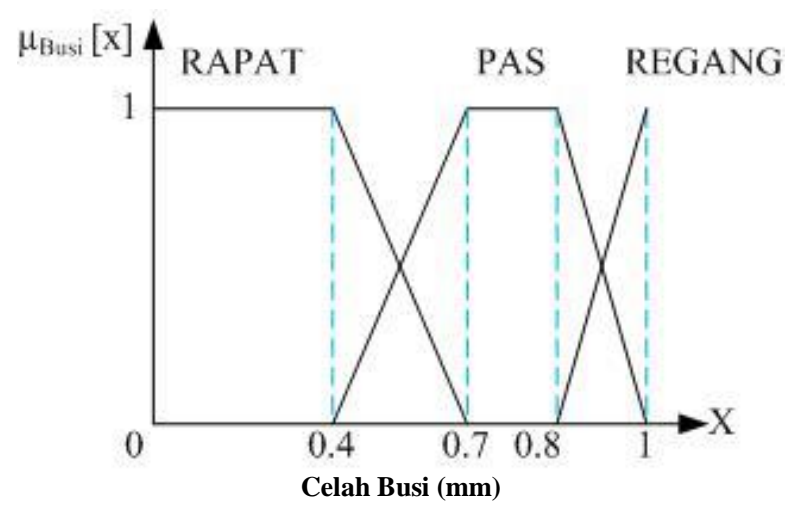

Gambar 3. Himpunan Fuzzy Variabel Celah Busi

Fungsi keanggotaan Celah Busi Rapat, Pas, dan Regang dapat dilihat pada persamanaan 1, 2, dan 3.

$$
\begin{aligned}
& \mu_{\text {busiRAPAT }}[\mathrm{x}]=\left\{\begin{array}{cc}
\frac{(0,7-x)}{(0,3)} ; & 0,4 \leq x \leq 0,7 \\
1 ; & x<0,4 \\
0 ; & x>0,7
\end{array}\right. \\
& \mu_{\text {busiPAS }}[\mathrm{x}]=\left\{\begin{array}{cc}
0 ; & x<0,4 \text { atau } x>1 \\
\frac{(x-0,4)}{(0,3)} ; & 0,4 \leq x \leq 0,7 \\
1 ; & 0,7<x<0,8 \\
\frac{(1-x)}{(0,2)} ; & 0,8 \leq x \leq 1
\end{array}\right. \\
& \mu_{\text {busiREGANG }}[\mathrm{x}]=\left\{\begin{array}{cc}
0 ; & x<0,8 \\
\frac{(x-0,8)}{(0,2)} ; & 0,8 \leq x \leq 1
\end{array}\right.
\end{aligned}
$$

b. Putaran Karburator

Himpunan fuzzy untuk variabel putaran karburator dapat dilihat pada gambar 4: 


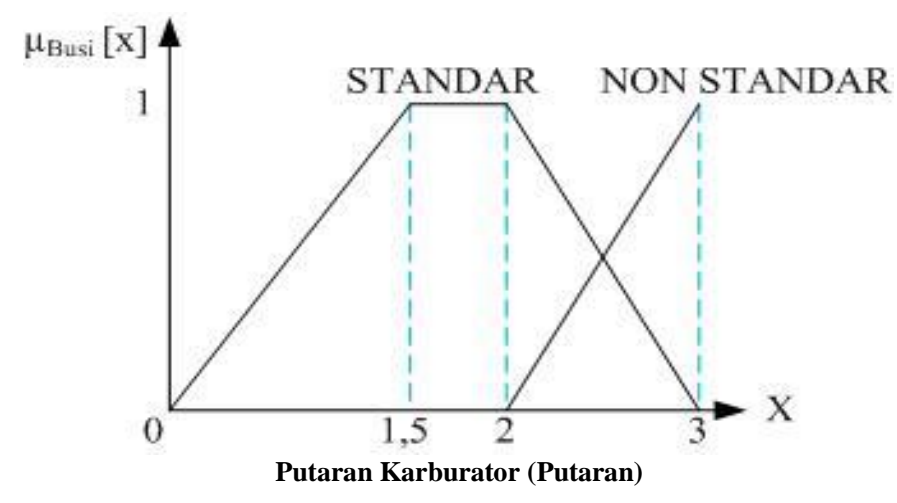

Gambar 4. Himpunan Variabel Putaran Karburator

Fungsi keanggotaan Putaran Karburator Standard an Non Standar dapat dilihat pada persamaan 4 dan 5 .

$$
\begin{aligned}
& \mu_{\text {karbuSTANDAR }[\mathrm{x}]}=\left\{\begin{array}{lc}
\frac{(x-0)}{(1,5)} ; & 0 \leq x \leq 1,5 \\
1 ; & 1,5<x<2 \\
0 ; & x>3 \\
\frac{(3-x)}{(1)} ; & 2 \leq x \leq 3
\end{array}\right. \\
& \mu_{\text {karbuNONSTANDAR }}[\mathrm{x}]=\left\{\begin{array}{cc}
0 ; & x<2 \\
\frac{(x-2)}{(1)} ; & 2 \leq x \leq 3
\end{array}\right.
\end{aligned}
$$

c. Celah Klep in

Himpunan fuzzy untuk variabel celah klep in dapat dilihat pada gambar 5

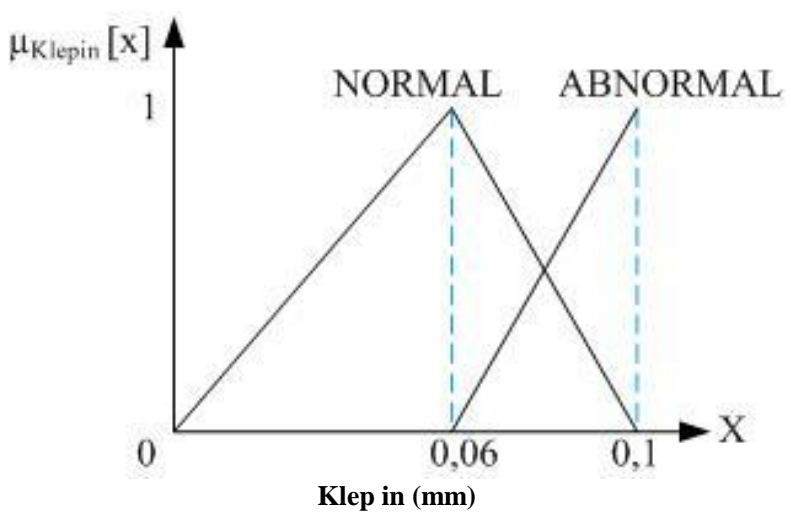

Gambar 5. Himpunan Fuzzy Variabel Klep In

Fungsi keanggotaan Klep in Normal dan Abnormal dapat dilihat pada persamaan 6 dan 7 .

$$
\begin{gathered}
\mu_{\text {klepinNORMAL }}[\mathrm{x}]=\left\{\begin{array}{cc}
\frac{(x-0)}{(0,06)} ; & 0 \leq x \leq 0,06 \\
0 ; & x>0,1 \\
\frac{(0,1-x)}{(0,04)} ; & 0,06 \leq x \leq 0,1
\end{array}\right. \\
\mu_{\text {klepinABNORMAL }}[\mathrm{x}]=\left\{\begin{array}{cc}
0 ; & x<0,06 \\
\frac{(x-0,06)}{(0,04)} ; & 0,06 \leq x \leq 0,1
\end{array}\right.
\end{gathered}
$$

d. Celah Klep ex

Himpunan fuzzy untuk variabel celah celah klep ex dapat dilihat pada gambar 6. 


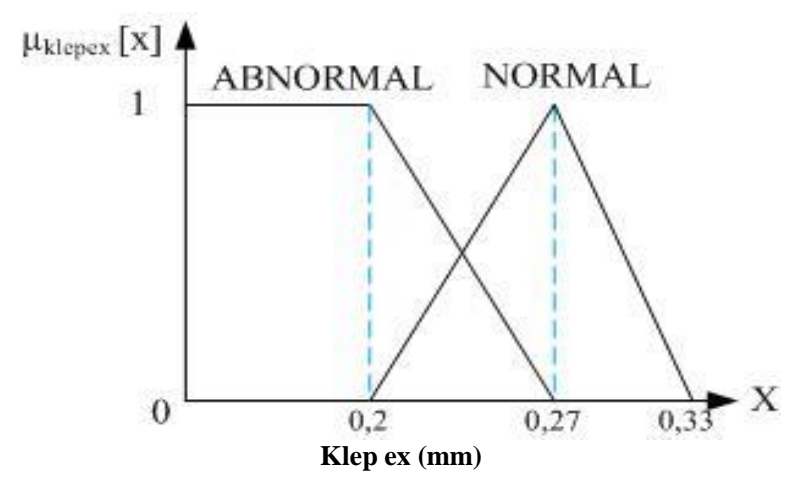

Gambar 6. Himpunan Fuzzy Variabel Celah Klep Ex

Fungsi keanggotaan Celah Klep Ex Abnormal dan Normal dapat dilihat pada persamaan 8 dan 9.

$$
\begin{gathered}
\mu_{\text {klepexNORMAL }}[\mathrm{x}]=\left\{\begin{array}{cc}
0 ; & x<0 \text { atau } x>0,3 \\
\frac{(x-0,2)}{(0,07)} ; & 0,2 \leq x \leq 0,27 \\
\frac{(0,33-x)}{(0,06)} & 0,27 \leq x \leq 0,33
\end{array}\right. \\
\mu_{\text {klepexABNORMAL }}[\mathrm{x}]=\left\{\begin{array}{cc}
\frac{(0,27-x)}{(0,07)} ; & 0.2 \leq x \leq 0,27 \\
1 ; & x \leq 0,2 \\
0 ; & x>0,27
\end{array}\right.
\end{gathered}
$$

e. Tingkat Kerusakan Mesin

Himpunan fuzzy untuk variabel tingkat kerusakan mesin dapat dilihat pada gambar 7.

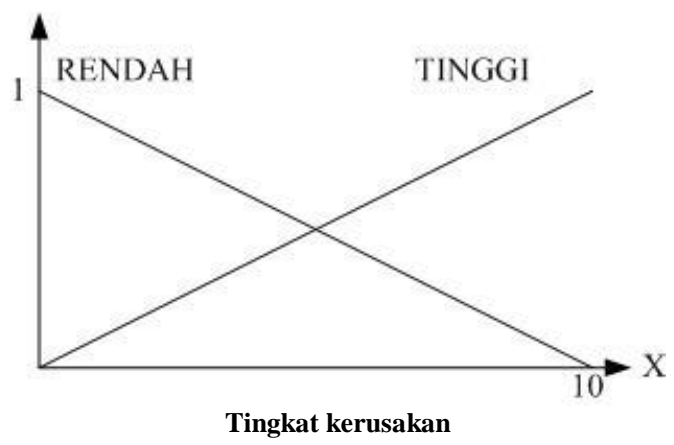

Gambar 7. Himpunan Fuzzy Variabel Tingkat Kerusakkan Mesin

Fungsi keanggotaan tingkat kerusakkan mesin Rendah dan Tinggi dapat dilihat pada persamaan 10 dan 11.

$$
\begin{array}{cc}
\mu_{\text {kerusakanRENDAH }}[\mathrm{x}]=\left\{\begin{array}{lc}
\frac{(10-x)}{(10)} ; & 0 \leq x \leq 10 \\
0 ; & x>10
\end{array}\right. \\
\mu_{\text {kerusakanTINGGI }}[\mathrm{x}]=\left\{\begin{array}{cc}
0 ; & x>10
\end{array}\right. \\
\frac{(x-0)}{(10)} ; & 0 \leq x \leq 10
\end{array}
$$

\subsection{Aturan Fuzzy}

Aturan fuzzy dibuat berdasarkan hasil diskusi dengan narasumber. Aturan fuzzy yang dibangun terdiri dari 24 aturan, aturan tersebut bisa dilihat pada tabel 1 . 
Tabel 1. Aturan fuzzy

\begin{tabular}{|c|c|}
\hline No. & Aturan \\
\hline 1 & $\begin{array}{l}\text { IF } 1 \text { PAS AND } 2 \text { STANDAR AND } 3 \text { NORMAL AND } 4 \text { NORMAL THEN kondisi } \\
\text { kerusakan mesin RENDAH }\end{array}$ \\
\hline 2 & $\begin{array}{l}\text { IF } 1 \text { REGANG AND } 2 \text { STANDAR AND } 3 \text { NORMAL AND } 4 \text { NORMAL THEN kondisi } \\
\text { kerusakan mesin RENDAH }\end{array}$ \\
\hline 3 & $\begin{array}{l}\text { IF } 1 \text { RAPAT AND } 2 \text { STANDAR AND } 3 \text { NORMAL AND } 4 \text { NORMAL THEN kondisi } \\
\text { kerusakan mesin RENDAH }\end{array}$ \\
\hline 4 & $\begin{array}{l}\text { IF } 1 \text { PAS AND } 2 \text { NON STANDAR AND } 3 \text { NORMAL AND } 4 \text { NORMAL THEN kondisi } \\
\text { kerusakan mesin RENDAH }\end{array}$ \\
\hline 5 & $\begin{array}{l}\text { IF } 1 \text { PAS AND } 2 \text { STANDAR AND } 3 \text { ABNORMAL AND } 4 \text { NORMAL THEN kondisi } \\
\text { kerusakan mesin RENDAH }\end{array}$ \\
\hline 6 & $\begin{array}{l}\text { IF } 1 \text { PAS AND } 2 \text { STANDAR AND } 3 \text { NORMAL AND } 4 \text { ABNORMAL THEN kondisi } \\
\text { kerusakan mesin RENDAH }\end{array}$ \\
\hline 7 & $\begin{array}{l}\text { IF } 1 \text { REGANG AND } 2 \text { NON STANDAR AND } 3 \text { NORMAL AND } 4 \text { NORMAL THEN } \\
\text { kondisi kerusakan mesin RENDAH }\end{array}$ \\
\hline 8 & $\begin{array}{l}\text { IF } 1 \text { RAPAT AND } 2 \text { NON STANDAR AND } 3 \text { NORMAL AND } 4 \text { NORMAL THEN } \\
\text { kondisi kerusakan mesin RENDAH }\end{array}$ \\
\hline 9 & $\begin{array}{l}\text { IF } 1 \text { REGANG AND } 2 \text { STANDAR AND } 3 \text { ABNORMAL AND } 4 \text { NORMAL THEN } \\
\text { kondisi kerusakan mesin TINGGI }\end{array}$ \\
\hline 10 & $\begin{array}{l}\text { IF } 1 \text { RAPAT AND } 2 \text { STANDAR AND } 3 \text { ABNORMAL AND } 4 \text { NORMAL THEN } \\
\text { kondisi kerusakan mesin TINGGI }\end{array}$ \\
\hline 11 & $\begin{array}{l}\text { IF } 1 \text { REGANG AND } 2 \text { STANDAR AND } 3 \text { NORMAL AND } 4 \text { ABNORMAL THEN } \\
\text { kondisi kerusakan mesin TINGGI }\end{array}$ \\
\hline 12 & $\begin{array}{l}\text { IF } 1 \text { RAPAT AND } 2 \text { STANDAR AND } 3 \text { NORMAL AND } 4 \text { ABNORMAL THEN } \\
\text { kondisi kerusakan mesin TINGGI }\end{array}$ \\
\hline 13 & $\begin{array}{l}\text { IF } 1 \text { PAS AND } 2 \text { NONSTANDAR AND } 3 \text { NORMAL AND } 4 \text { ABNORMAL THEN } \\
\text { kondisi kerusakan mesin TINGGI }\end{array}$ \\
\hline 14 & $\begin{array}{l}\text { IF } 1 \text { PAS AND } 2 \text { NONSTANDAR AND } 3 \text { ABNORMAL AND } 4 \text { NORMAL THEN } \\
\text { kondisi kerusakan mesin TINGGI }\end{array}$ \\
\hline 15 & $\begin{array}{l}\text { IF } 1 \text { PAS AND } 2 \text { STANDAR AND } 3 \text { ABNORMAL AND } 4 \text { ABNORMAL THEN } \\
\text { kondisi kerusakan mesin TINGGI }\end{array}$ \\
\hline 16 & $\begin{array}{l}\text { IF } 1 \text { REGANG AND } 2 \text { NONSTANDAR AND } 3 \text { ABNORMAL AND } 4 \text { NORMAL } \\
\text { THEN kondisi kerusakan mesin TINGGI }\end{array}$ \\
\hline 17 & $\begin{array}{l}\text { IF } 1 \text { RAPAT AND } 2 \text { NONSTANDAR AND } 3 \text { ABNORMAL AND } 4 \text { NORMAL THEN } \\
\text { kondisi kerusakan mesin TINGGI }\end{array}$ \\
\hline 18 & $\begin{array}{l}\text { IF } 1 \text { REGANG AND } 2 \text { NONSTANDAR AND } 3 \text { NORMAL AND } 4 \text { ABNORMAL } \\
\text { THEN kondisi kerusakan mesin TINGGI }\end{array}$ \\
\hline 19 & $\begin{array}{l}\text { IF } 1 \text { RAPAT AND } 2 \text { NONSTANDAR AND } 3 \text { NORMAL AND } 4 \text { ABNORMAL THEN } \\
\text { kondisi kerusakan mesin TINGGI }\end{array}$ \\
\hline 20 & $\begin{array}{l}\text { IF } 1 \text { REGANG AND } 2 \text { STANDAR AND } 3 \text { ABNORMAL AND } 4 \text { ABNORMAL THEN } \\
\text { kondisi kerusakan mesin TINGGI }\end{array}$ \\
\hline 21 & $\begin{array}{l}\text { IF } 1 \text { RAPAT AND } 2 \text { STANDAR AND } 3 \text { ABNORMAL AND } 4 \text { ABNORMAL THEN } \\
\text { kondisi kerusakan mesin TINGGI }\end{array}$ \\
\hline 22 & $\begin{array}{l}\text { IF } 1 \text { PAS AND } 2 \text { NONSTANDAR AND } 3 \text { ABNORMAL AND } 4 \text { ABNORMAL THEN } \\
\text { kondisi kerusakan mesin TINGGI }\end{array}$ \\
\hline 23 & $\begin{array}{l}\text { IF } 1 \text { REGANG AND } 2 \text { NONSTANDAR AND } 3 \text { ABNORMAL AND } 4 \text { ABNORMAL } \\
\text { THEN kondisi kerusakan mesin TINGGI }\end{array}$ \\
\hline 24 & $\begin{array}{l}\text { IF } 1 \text { RAPAT AND } 2 \text { NONSTANDAR AND } 3 \text { ABNORMAL AND } 4 \text { ABNORMAL } \\
\text { THEN kondisi kerusakan mesin TINGGI }\end{array}$ \\
\hline
\end{tabular}

Keterangan :

1 : Celah busi

2 : Putaran karburator

3 : Celah Klepin

4 : Celah Klepex 


\subsection{Hasil Pengujian}

Pengujian perhitungan dilakukan dengan cara membandingkan hasil penentuan kondisi kerusakan mesin yang telah dilakukan narasumber dengan hasil penentuan kondisi kerusakan mesin menggunakan aplikasi. Hasil pengujian perhitungan dapat dilihat pada tabel 2.

Tabel 2. Tabel hasil pengujian perhitungan

\begin{tabular}{cllllccc}
\hline No & $\begin{array}{c}\boldsymbol{A} \\
(\mathbf{m m})\end{array}$ & $\begin{array}{c}\boldsymbol{B} \\
(\text { Putaran })\end{array}$ & $\begin{array}{c}\boldsymbol{C} \\
(\mathbf{m m})\end{array}$ & $\begin{array}{c}\boldsymbol{D} \\
(\mathbf{m m})\end{array}$ & $\begin{array}{c}\text { Output } \\
\text { Logika } \boldsymbol{F u z z y}\end{array}$ & $\begin{array}{c}\text { Hasil } \\
\text { sistem }\end{array}$ & $\begin{array}{c}\text { Pendapat } \\
\text { Narasumber }\end{array}$ \\
\hline 1 & 0,5 & 2,2 & 0,083 & 0,24 & 5,3645 & Tinggi & Tinggi \\
2 & 0,7 & 1,7 & 0,075 & 0,27 & 3,6742 & Rendah & Rendah \\
3 & 0,92 & 2,4 & 0,09 & 0,23 & 5,4343 & Tinggi & Tinggi \\
4 & 0,5 & 1,9 & 0,091 & 0,29 & 5,8024 & Tinggi & Tinggi \\
5 & 1 & 2,8 & 0,085 & 0,2 & 6,3257 & Tinggi & Tinggi \\
6 & 0,89 & 2,18 & 0,04 & 0,28 & 3,7988 & Rendah & Rendah \\
7 & 0,8 & 1,6 & 0,087 & 0,21 & 5,8392 & Tinggi & Tinggi \\
8 & 0,52 & 1,4 & 0,05 & 0,22 & 5,4933 & Tinggi & Tinggi \\
9 & 0,3 & 2,7 & 0,02 & 0,2 & 5,7777 & Tinggi & Tinggi \\
10 & 1 & 3 & 0,1 & 0,2 & 5,7051 & Tinggi & Tinggi \\
11 & 0,9 & 2,9 & 0,09 & 0,23 & 6,6666 & Tinggi & Tinggi \\
12 & 0,52 & 1,2 & 0,021 & 0,235 & 4,7888 & Tinggi & Tinggi \\
13 & 0,7 & 1 & 0,03 & 0,31 & 4,2222 & Rendah & Tinggi \\
14 & 0,83 & 0,5 & 0,01 & 0,32 & 4,5959 & Tinggi & Tinggi \\
15 & 0,9 & 2,3 & 0,09 & 0,24 & 5 & Tinggi & Tinggi \\
16 & 0,4 & 3 & 0,1 & 0,2 & 6,6666 & Tinggi & Tinggi \\
17 & 0,53 & 2,52 & 0,078 & 0,24 & 4,8204 & Tinggi & Rendah \\
18 & 0,4 & 3 & 0,062 & 0,26 & 3,5179 & Rendah & Rendah \\
19 & 0,44 & 2,27 & 0,063 & 0,282 & 3,5622 & Rendah & Rendah \\
20 & 1 & 2,6 & 0,09 & 0,29 & 5,9081 & Tinggi & Tinggi \\
21 & 0,78 & 1,78 & 0,06 & 0,27 & 3,3333 & Rendah & Rendah \\
22 & 0,48 & 1,6 & 0,06 & 0,27 & 3,5204 & Rendah & Rendah \\
23 & 0,88 & 1,7 & 0,06 & 0,27 & 3,7142 & Rendah & Rendah \\
24 & 0,85 & 1,49 & 0,089 & 0,31 & 4,7222 & Tinggi & Tinggi \\
25 & 0,92 & 2,12 & 0,066 & 0,277 & 3,8652 & Ringan & Ringan \\
26 & 0,8 & 2,1 & 0,083 & 0,27 & 3,8271 & Rendah & Tinggi \\
27 & 0,52 & 1,45 & 0,056 & 0,26 & 3,8520 & Rendah & Rendah \\
28 & 0,66 & 2,8 & 0,04 & 0,28 & 3,6111 & Rendah & Rendah \\
29 & 0,69 & 1,49 & 0,058 & 0,265 & 3,3565 & Rendah & Rendah \\
30 & 0,69 & 1,44 & 0,049 & 0,22 & 3,5526 & Rendah & Rendah \\
\hline
\end{tabular}

Keterangan tabel:
A : Celah Busi
B : Putaran Karburator
C : Celah Klepin
D : Celah Klepex

Berdasarkan data tabel pengujian, diketahui dari 30 kasus terdapat 3 kasus gagal. Maka dapat di simpulkan bahwa algoritma yang di gunakan memberikan performansi dengan tingkat error $10 \%$.

\section{KESIMPULAN}

Kesimpulan yang didapat dari hasil pengujian perhitungan aplikasi penentuan kondisi mesin pada sepeda motor transmisi manual (studi kasus Honda CS-1) yaitu tingkat error untuk menentukan kondisi kerusakan mesin adalah 10\%. Performansi algoritma yang digunakan dapat ditingkatkan dengan memperbaiki fungsi keanggotaan pada masing-masing variabel fuzzy.

\section{DAFTAR PUSTAKA}

[1] Kusumadewi S, 2002, “Analisa dan Desain Sistem Fuzzy”, Graha Ilmu, Yogyakarta.

[2] Alnahhas, A. and Alkhatib, B. 2012, "Decision support system for crisis management using temporal fuzzy logic", 2012 6th International Conference on Application of Information and Communication Technologies, Georgia. 
[3] Juan, S., et al., 2004, "An application of the analytic hierarchy process and fuzzy logicinference in a decision support system for forage selection". New Zealand Journal of Agricultural Research, Vol. 47, issue 3, pp. 327-331.

[4] Makropoulos, C.K., et al., 2003, "Fuzzy logic spatial decision support system for urban water management”, Journal of Water Resources Planning and Management, Vol. 129, isuue 1, pp. 69-77.

[5] Patel, A., et al., 2012, "Decision support system for the diagnosis of asthma severity using fuzzy logic", International MultiConference of Engineers and Computer Scientists, IMECS 2012, Kowloon, pp. 142-147.

[6] Patel, J., et al., 2012, "Fuzzy logic based Decision Support System framework for irrigation scheduling”, 3rd Nirma University International Conference on Engineering, NUiCONE 2012, Gujarad, pp. 1-4.

[7] Samuel, O.W., et al., 2013, "A web based decision support system driven by fuzzy logic for the diagnosis of typhoid fever. Expert Systems with Applications”, Vol. 40, Issue 10, pp. 4164-4171.

[8] Thang, C., et al., 2005, "A decision support system for rheumatic evaluation and treatment in oriental medicine using fuzzy logic and neural network", 2nd International Conference on Modeling Decisions for Artificial Intelligence, MDAI 2005, Tsukuba, pp. 399-409.

[9] Fitrianty D. A., et al., 2013, "Ketepatan Klasifikasi Dengan Analisis Regresi Logistik Dan Multivariative Adaptive Regression Splines (MARS) Pada Data Dengan Peubah Respon Biner", Jurnal Mahasiswa Statistik, vol. 1 no. 4, pp. 269-272. 